\title{
Mobile learning application berbasis sublime text pada mata pelajaran kearsipan
}

\author{
Binti Itsnania, I Nyoman Suputra* \\ Universitas Negeri Malang, Jl. Semarang No. 5 Malang, Jawa Timur, Indonesia \\ *Penulis korespondensi, Surel: nyoman.suputra.fe@um.ac.id
}

Paper received: 25-8-2021; revised: 8-9-2021; accepted: 15-9-2021

\begin{abstract}
As the effects of Covid-19 pandemic, Indonesia's education experienced numerous changes. The previously face-to-face learning activities have been replaced by the online learning that relies on Internet access. Meanwhile, during a learning process, teachers use media to facilitate students learning. Therefore, the implementation of online learning rises the need for learning media in online learning. Mobile learning is invented as a learning media that can be implemented in this situation. It is developed using a number of programing applications, such as Sublime Text, to generate user friendly media. This study developed a Sublime Text based mobile learning application that can be accessed through android smartphones. This media has been confirmed to help teachers deliver learning materials, learning videos, and exercises accessible at anytime and anywhere. This Sublime Text based mobile learning application is called Study Fill. The learning media has been tried out to the students in tenth grade of State Vocational High School 2 Kediri, while the result suggest that the learning media is feasible and valid.
\end{abstract}

Keywords: Research and development; mobile learning; sublime text; study fill

\begin{abstract}
Abstrak
Pendidikan di Indonesia saat ini mengalami perubahan karena dampak dari pandemi Covid-19. Kegiatan belajar mengajar yang sebelumnya dapat dilakukan secara tatap muka di sekolah, saat ini ditiadakan dan diganti dengan kegiatan pembelajaran secara jarak jauh. Pembelajaran jarak jauh mengandalkan akses internet sebagai sarana pembelajaran. Pada kegiatan belajar mengajar, guru biasanya memanfaatkan media yang dapat digunakan untuk membantu berlangsungnya proses pembelajaran. Berkaitan dengan hal tersebut, dibutuhkan media pembelajaran yang tepat sehingga dapat membantu guru dalam pembelajaran daring. Mobile learning merupakan salah satu media yang tepat untuk mengatasi masalah tersebut. Mobile learning dapat dikembangkan dengan menggunakan beberapa aplikasi pemrograman, seperti Sublime Text, sehingga dapat menghasilkan aplikasi yang bersifat user friendly. Hasil penelitian ini berupa Mobile Learning Application berbasis Sublime Text yang dapat diakses melalui smartphone android. berupa Mobile Learning Application berbasis Sublime Text terbukti mempermudah guru membagikan materi, video pembelajaran maupun soal-soal dan peserta didik dapat mengaksesnya dimanapun dan kapanpun. Mobile Learning Application berbasis Sublime Text yang diberi nama StudyFill ini layak digunakan untuk siswa kelas X OTKP SMK Negeri 2 Kediri karena memperoleh hasil validasi sangat valid.
\end{abstract}

Kata kunci: Penelitian dan Pengembangan; Mobile Learning; Sublime text; Study Fill

\section{Pendahuluan}

Kegiatan belajar mengajar via daring di masa pandemi ini lebih mengandalkan akses internet sebagai sarana pembelajaran. Pada kegiatan belajar mengajar, guru biasanya memanfaatkan media yang dapat digunakan untuk membantu berlangsungnya proses pembelajaran. Beberapa contohnya yaitu, google classroom, WhatsApp, Zoom dan lain lain. Penggunaan media pembelajaran ini tentu memiliki kelebihan dan kekurangan. Hal tersebut membuat guru harus memilih media pembelajaran yang tepat untuk digunakan dalam pembelajaran. 
Pemilihan media pembelajaran perlu disesuaikan dengan kebutuhan, situasi dan kondisi. Seorang guru harus mampu menyelaraskan antara media dan metode pembelajaran agar peserta didik lebih mudah menerima dan memahami pembelajaran. Namun, saat ini, seringkali guru kurang memanfaatkan media pembelajaran yang ada sehingga kegiatan belajar mengajar terkesan monoton dan membosankan bagi peserta didik.

Penggunaan media berperan penting dalam penyampaian informasi dan pengetahuan serta mempermudah proses kegiatan belajar mengajar. Selain itu, media pembelajaran juga dapat membuat aktivitas belajar menjadi lebih menarik sehingga dapat meningkatkan motivasi belajar siswa (Pribadi, 2017). Peserta didik juga akan lebih mudah untuk berkonsentrasi dalam memahami pelajaran yang disampaikan guru.

Mobile learning merupakan pembelajaran dalam berbagai konteks, melalui interaksi sosial dengan menggunakan perangkat elektronik (Bernacki et al., 2020). Perangkat elektronik yang digunakan, biasanya didukung oleh jaringan internet yang dapat membantu membantu untuk menjelajahi beberapa situs atau program pembelajaran lain agar cakupan pembelajarannya lebih luas.

Penelitian ini penting dilakukan karena telah dilakukan sebelumnya oleh (Crompton \& Burke, 2018) yang membuktikan bahwa penggunaan mobile learning dapat meningkatkan hasil belajar siswa. Pembelajaran mobile learning dapat diikuti oleh siswa dengan mudah dengan membutuhkan perangkat seluler dan jaringan internet. Selain itu, mobile learning juga memudahkan peserta maupun guru. Sedangkan penelitian lain yang relevan yaitu oleh (Azlan et al., 2020) diperoleh hasil bahwa pembelajaran yang saat ini dialihkan menjadi pembelajaran secara daring di masa pandemi Covid-19, memiliki banyak manfaat bagi guru maupun peserta didik. Guru dapat lebih mengembangkan model pembelajaran seperti apa yang cocok digunakan untuk peserta didik dengan memperhatikan kondisi dan kemampuan peserta didiknya.

\section{Hasil dan Pembahasan}

Bagian ini memaparkan pengertian dari Mobile Learning, Sublime Text dan StudyFill. Berikut masing-masing penjelasannya.

\subsection{Mobile Learning}

Mobile learning merupakan salah satu generasi dari e-learning yang memanfaatkan jaringan internet/nirkabel (wireless) (El-Sofany \& El-Haggar, 2020). Fitur utama dan manfaat mobile learning tidak terbatas pada waktu. Peserta didik dapat mengakses mobile learning dimanapun dan kapanpun, serta guru dapat memberi materi pembelajaran tidak terbatas tempat dan waktu.

Sedangkan menurut Crompton (dalam Bernacki et al., 2020), mobile learning merupakan pembelajaran dalam berbagai konteks, melalui interaksi sosial dengan menggunakan perangkat elektronik.

\subsection{Sublime Text}

Menurut Putra, dkk (dalam Pradiatiningtyas \& Suparwanto, 2017), Sublime Text adalah text editor berbasis Python, sebuah text editor yang elegan, kaya fitur, cross platform, mudah 
dan simple yang cukup terkenal dikalangan developer (pengembang) dan desainer. Sublime Text digunakan sebagai editor dari bahasa pemrograman PHP dalam melakukan pengelolaan konten di dalam aplikasi server.

\subsection{StudyFill}

Hasil pengembangan media pembelajaran pada penelitian ini adalah sebuah aplikasi bernama StudyFill. Aplikasi ini memuat materi mata pelajaran Kearsipan lengkap beserta video pembelajaran, latihan soal dan latihan praktek. Berikut beberapa tampilan awal dari aplikasi StudyFill pada gambar 1 .

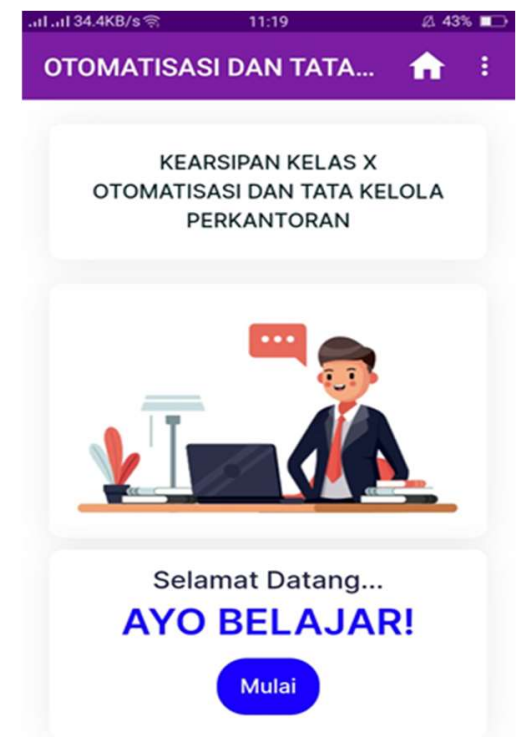

Gambar 1. Tampilan Menu Awal

Pada gambar 2, akan ditampilkan menu secara keseluruhan dari media pembelajaran Mobile Learning Application ini. Adapun menu yang ditampilkan yaitu KI/KD, materi, video pembelajaran, latihan soal, soal praktek, serta bantuan.

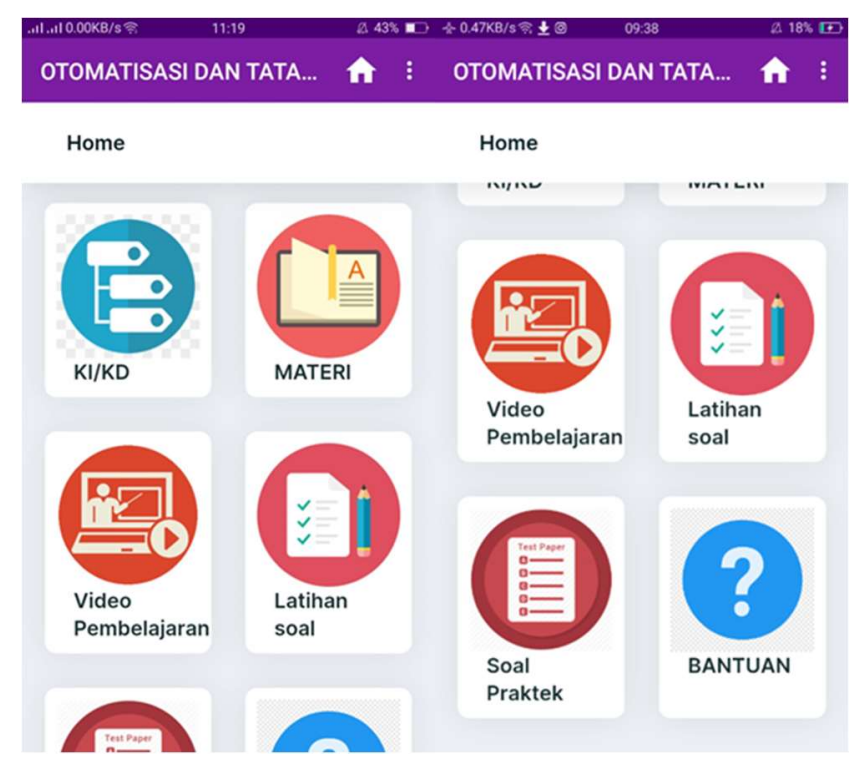

Gambar 2. Tampilan Menu Utama Aplikasi 
Pada gambar 3 memuat kompetensi inti dan kompetensi dasar sesuai dengan mata pelajaran Kearsipan semester II.

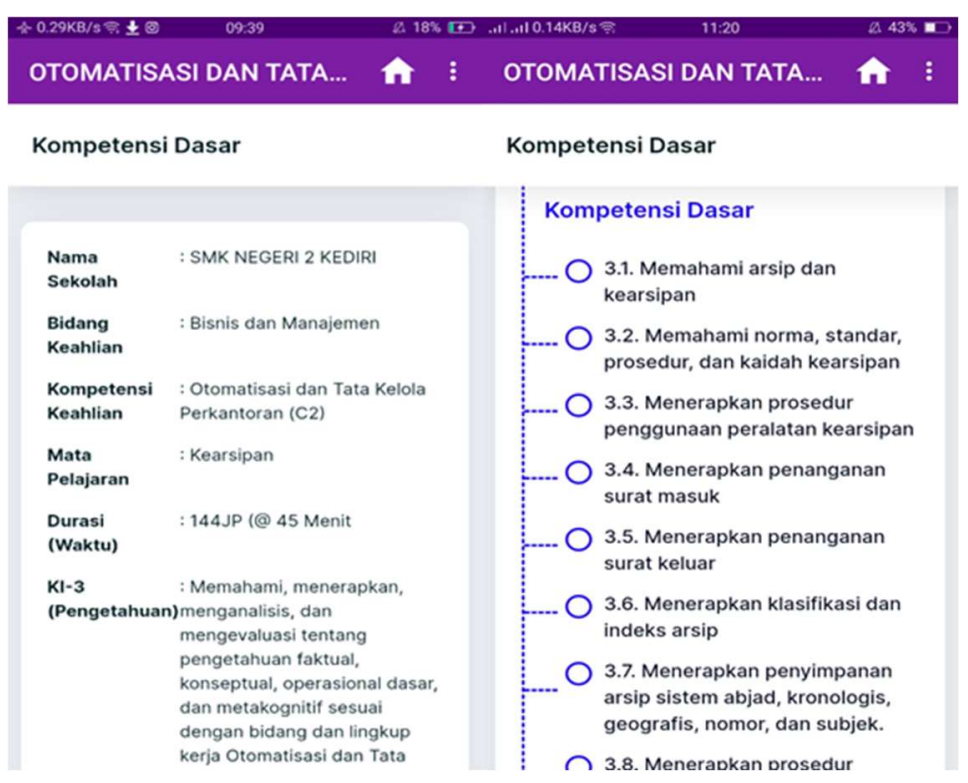

\section{Gambar 3. Tampilan Menu KI/KD}

Pada gambar 4 terdapat menu materi yang terdiri dari 7 kompetensi dasar. Peserta didik dapat memilih materi yang ingin dipelajari.

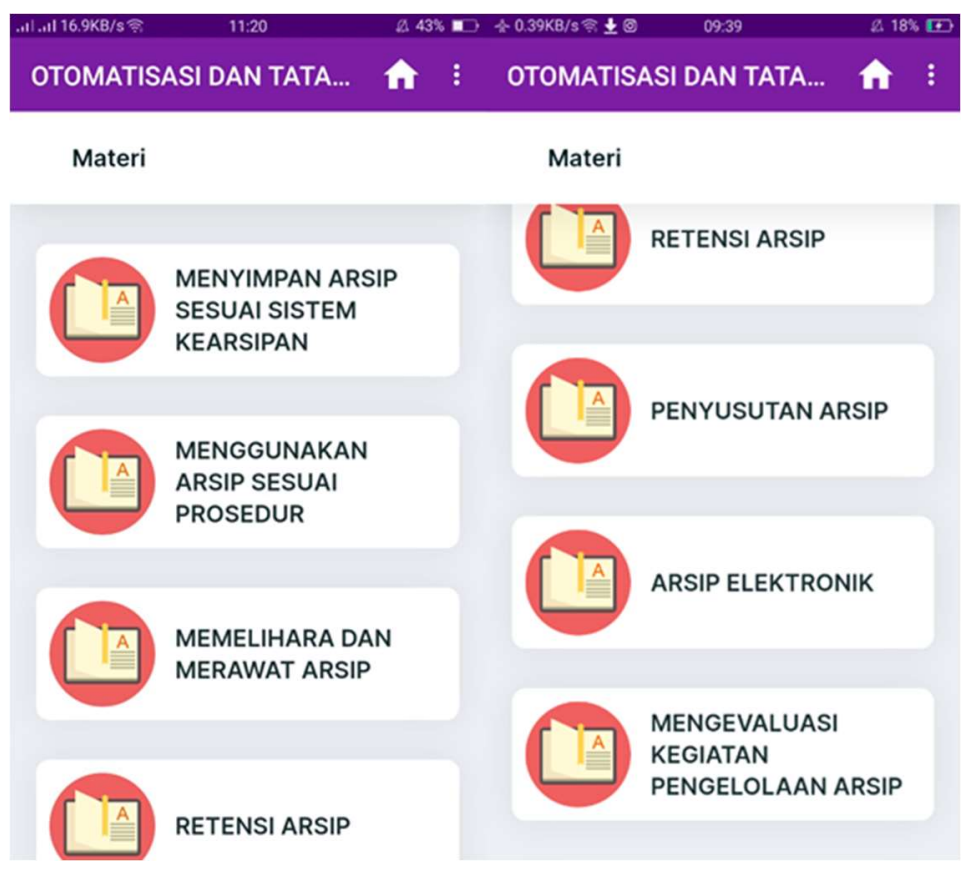

\section{Gambar 4. Tampilan Menu Materi}

Pada gambar 5 memuat rangkuman materi. Peserta didik dapat mengunduh materi tersebut ataupun dapat dipelajari melalui aplikasi ini. 


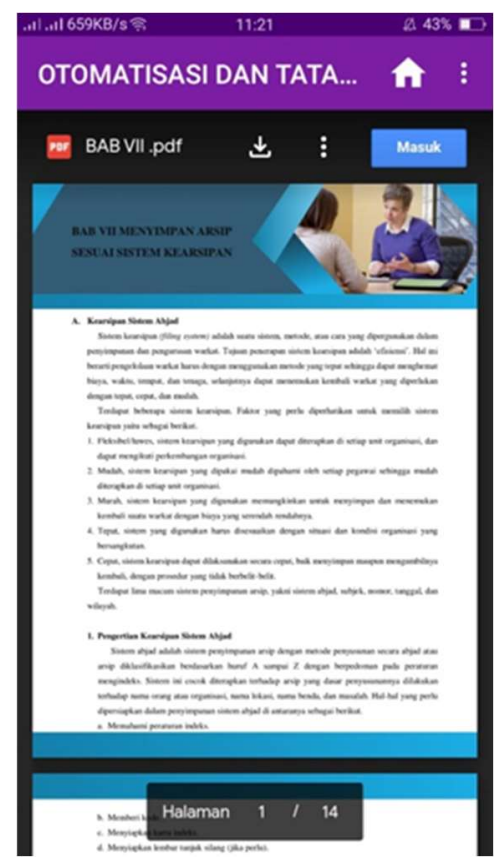

Gambar 5. Tampilan Isi Materi

Pada gambar 6 terdapat menu yang berisi video-video pembelajaran yang menarik terkait penjelasan materi.

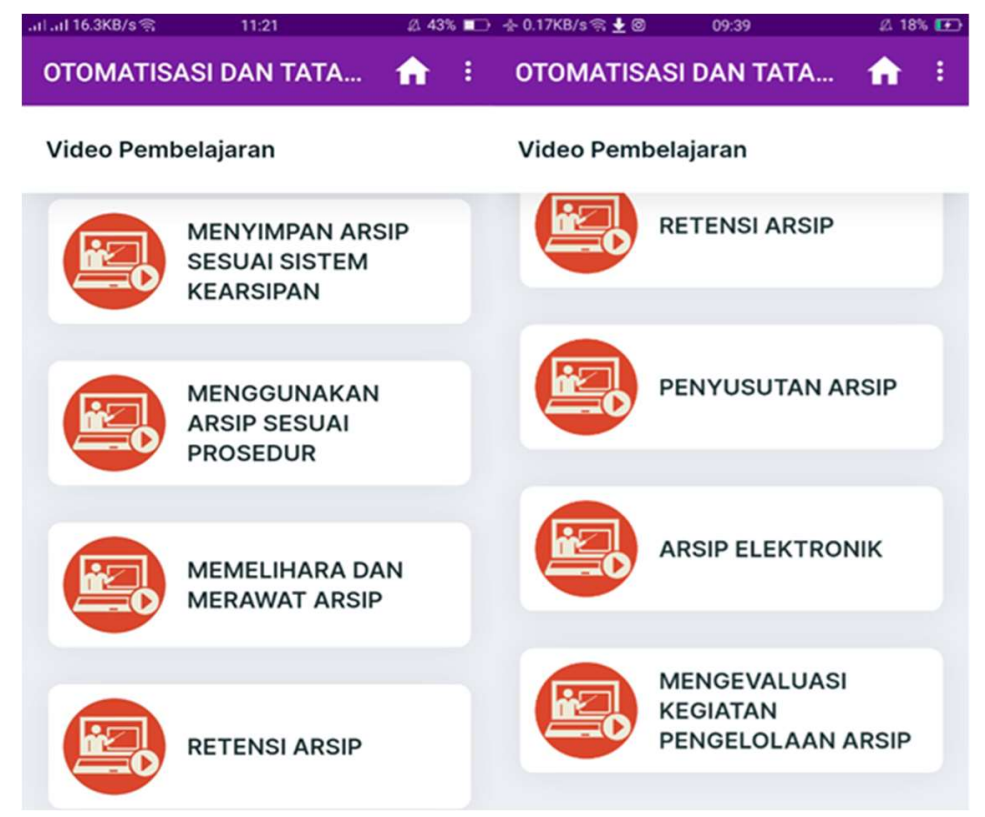

\section{Gambar 6. Tampilan Menu Video Pembelajaran}

Pada gambar 7 terdapat menu yang berisi soal-soal latihan untuk peserta didik. 
Jurnal Ekonomi, Bisnis dan Pendidikan, 1(9), 2021, 914-921

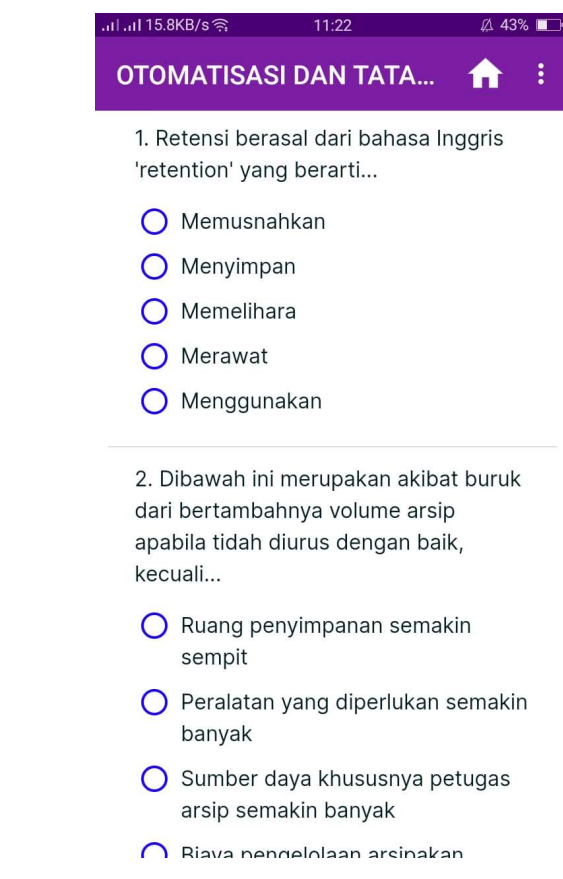

\section{Gambar 7. Tampilan Latihan Soal Pilihan Ganda}

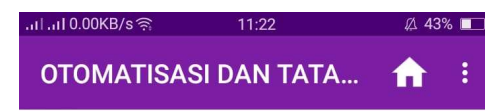

Kegiatan 4.8

1. Carilah 15 contoh surat di internet untuk kegiatan praktek.

2. Persiapkan semua alat dan bahan yang diperlukan!

3. Tentukan sistem arsip yang akan digunakan

4. Buatlah perencanaan untuk

mempraktikkan cara penemuan

kembali arsip disimpan berdasarkan

system yang kalian pilih!

5. Kumpulkan hasil pekerjaan kalian

kepada guru mata pelajaran!

\section{Gambar 8. Tampilan Menu Latihan Soal Praktek}

Pada gambar 8 terdapat beberapa soal praktek sesuai dengan kompetensi dasar mata pelajaran Kearsipan.

\section{Simpulan}

Mobile learning Application adalah media yang digunakan dalam proses pembelajaran dengan mengakses aplikasi pada smartphone android sehingga dapat mempermudah peserta 
didik dan guru dalam mencapai tujuan pembelajaran. Dalam penelitian ini, mobile learning application dikembangkan menggunakan software Sublime Text yang memuat materi, video pembelajaran dan soal-soal pembelajaran.

Hasil penelitian dan pengembangan ini berupa aplikasi media pembelajaran berbasis smartphone android bernama StudyFill yang dapat di instal melalui link http://bit.ly/StudyFill dan dapat diakses melalui smartphone android. Aplikasi ini memiliki berbagai fitur pembelajaran antara lain menu materi, video pembelajaran, soal latihan yang berbentuk pilihan ganda, serta soal praktek. Mobile Learning Application layak digunakan untuk siswa kelas X OTKP SMK Negeri 2 Kediri karena dapat mempermudah guru dalam melaksanakan pembelajaran secara daring dan sebagai salah satu sumber belajar bagi peserta didik. Aplikasi ini dinyatakan sangat valid oleh ahli media dengan perolehan skor validasi sebesar $99 \%$. Sedangkan, perolehan skor dari ahli materi sebesar 87,77\% dengan kriteria kevalidan sangat valid. Pada uji coba kelompok kecil yang dilakukan kepada peserta didik diperoleh skor sebesar 93,82\% dengan kriteria sangat valid sehingga layak digunakan. Saran bagi peneliti lain agar bisa mengembangkan media pembelajaran dalam bentuk aplikasi lebih menarik dan memiliki fitur yang lengkap serta dapat mengunggah aplikasi ke platform yang lebih luas yaitu PlayStore agar pengguna lain dapat menginstall dengan mudah.

\section{Ucapan Terima Kasih (Opsional)}

Peneliti mengucapkan terima kasih kepada Universitas Negeri Malang yang telah memfasilitasi dan memungkinkan peneliti untuk melakukan penelitian dan pengembangan ini.

\section{Daftar Rujukan}

Akbar, S. (2017). Instrumen Perangkat Pembelajaran. Bandung, Rosda.

Arsyad, Azhar. (2014). Media Pembelajaran. Jakarta, RajaGrafindo Persada.

Azlan, C. A., Wong, J. H. D., Tan, L. K., Muhammad Shahrun, M. S. N., Ung, N. M., Pallath, V., Tan, C. P. L., Yeong, C. H., \& Ng, K. H. (2020). Teaching and learning of postgraduate medical physics using Internet-based elearning during the COVID-19 pandemic - A case study from Malaysia. Physica Medica, 80(July), 10-16. https://doi.org/10.1016/j.ejmp.2020.10.002

Bernacki, M. L., Greene, J. A., \& Crompton, H. (2020). Mobile technology, learning, and achievement: Advances in understanding and measuring the role of mobile technology in education. Contemporary Educational Psychology, 60(November 2019). https://doi.org/10.1016/j.cedpsych.2019.101827

Crompton, H., \& Burke, D. (2018). The use of mobile learning in higher education: A systematic review. Computers and Education, 123(April), 53-64. https://doi.org/10.1016/j.compedu.2018.04.007

El-Sofany, H. F., \& El-Haggar, N. (2020). The effectiveness of using mobile learning techniques to improve learning outcomes in higher education. International Journal of Interactive Mobile Technologies, 14(8), 4-18. https://doi.org/10.3991/IJIM.V14I08.13125

Hardika, Aisyah, E. N., Raharjo, K. M., \& Soraya, D. U. (2020). Transformation the meaning of learning for millennial generation on digital era. International Journal of Interactive Mobile Technologies, 14(12), 69-81. https://doi.org/10.3991/IJIM.V14I12.15579

Hendryadi. (2017). Validitas Isi: Tahap Awal Pengembangan Kuesioner. Jurnal Riset Manajemen Dan Bisnis (JRMB) 2(2), Fakultas Ekonomi UNIAT. https://doi.org/https://doi.org/10.36226/jrmb.v2i2.47

Hidayati, K., \& Listyani, E. (2010). Pengembangan Instrumen Kemandirian Belajar Mahasiswa. In Jurnal Penelitian dan Evaluasi Pendidikan (Vol. 14, Issue 1). https://doi.org/10.21831/pep.v14i1.1977

Jalinus, N., \& A, A. (2016). Media Dan Sumber Pembelajaran. http://repository.unp.ac.id/21330/

Klimova, B. (2020). Benefits of the use of mobile applications for learning a foreign language by elderly population. Procedia Computer Science, 176, 2184-2191. https://doi.org/10.1016/j.procs.2020.09.255 
Lestari, I., Maksum, A., \& Kustandi, C. (2019). Mobile learning design models for State University of Jakarta, Indonesia. International Journal of Interactive Mobile Technologies, 13(9), 152-171. https://doi.org/10.3991/ijim.v13i09.10987

Mishra, S. (2020). Learning from Usage Analysis of Mobile Devices. Procedia Computer Science, 167(2019), 1648-1655. https://doi.org/10.1016/j.procs.2020.03.375

Muyaroah, S., \& Fajartia, M. (2017). Pengembangan Media Pembelajaran Berbasis Android dengan menggunakan Aplikasi Adobe Flash CS 6 pada Mata Pelajaran Biologi. Innovative Journal of Curriculum and Educational Technology, 6(2), 22-26. https://doi.org/10.15294/ijcet.v6i2.19336

Pradiatiningtyas, D., \& Suparwanto. (2017). E-Learning Sebagai Media Pembelajaran Berbasis Web Pada Smk $\mathrm{N} 4$ Purworejo. Indonesian Journal on Networking and Security, 7(2), 1-8. https://ijns.org/journal/index.php/ijns/article/download/1499/1460

Pribadi, B. (2017). Media \& Teknologi dalam Pembelajaran. Jakarta, KENCANA.

Purba, N., \& Tarigan, N. (2019). The Effect of Use the Camtasia Studio 8 Learning Media on Student Learning Outcomes in Class VII Middle School Swasta Jambi Medan. Journal of Education and Practice, 10(18), 16-19. https://doi.org/10.7176/jep/10-18-03

Rahmat, R. F., Mursyida, L., Rizal, F., Krismadinata, K., \& Yunus, Y. (2019). Pengembangan media pembelajaran berbasis mobile learning pada mata pelajaran simulasi digital. Jurnal Inovasi Teknologi Pendidikan, 6(2), 116-126. https://doi.org/10.21831/jitp.v6i2.27414

Rohmah, F. N., \& Bukhori, I. (2020). Pengembangan Media Pembelajaran Interaktif Mata Pelajaran Korespondensi Berbasis Android Menggunakan Articulate Storyline 3. Economic \& Education Journal, 2, 169-182.

Shuib, M., Abdullah, A., Azizan, S. N., \& Gunasegaran, T. (2015). Designing an intelligent mobile learning tool for grammar learning (i-MoL). International Journal of Interactive Mobile Technologies, 9(1), 41-46. https://doi.org/10.3991/ijim.v9i1.4238

Sugiyono. (2011). Metode Penelitian Pendidikan Pendekatan Kuantitatif, Kualitatif, dan R\&D. Bandung, Alfabeta.

Sugiyono. (2016). Metode Penelitian Kuantitatif, Kualitatif, dan R\&D. Bandung, Alfabeta.

Surahman, E. (2019). Integrated Mobile Learning System (Imoles) Sebagai Upaya Mewujudkan Masyarakat Pebelajar Unggul Era Digital. JINOTEP (Jurnal Inovasi Dan Teknologi Pembelajaran) Kajian Dan Riset Dalam Teknologi Pembelajaran, 5(2), 50-56. https://doi.org/10.17977/um031v5i22019p050

Wang, J. Y., Wu, H. K., \& Hsu, Y. S. (2017). Using mobile applications for learning: Effects of simulation design, visual-motor integration, and spatial ability on high school students' conceptual understanding. Computers in Human Behavior, 66, 103-113. https://doi.org/10.1016/j.chb.2016.09.032

Winarno. (2014). Pengantar Pendidikan. Universitas Negeri Malang.

Wulandari, D. A., Wibawanto, H., Suryanto, A., \& Murnomo, A. (2019). Pengembangan Mobile Learning berbasis Android pada Mata Pelajaran Rekayasa Perangkat Lunak di SMK Sultan Trenggono Kota Semarang. Jurnal Teknologi Informasi Dan Ilmu Komputer, 6(5), 577. https://doi.org/10.25126/jtiik.201965994 